\title{
Extending Knowledge Domains for New Media Education: Integrating Interaction Design Theory and Methods
}

\author{
Anthony Faiola \\ Indiana University School of Informatics, Indianapolis, USA
}

\section{Stephen Boyd Davis}

Middlesex University, London

\section{Richard Edwards}

Indiana University School of Informatics, Indianapolis, USA

\begin{abstract}
Over the last ten years, new media has ascended to a prominent place in many fields that utilize communication technologies. At the same time, new media education has evolved in such a way that students are often not prepared to understand the social context of new media design and development. To produce new media professionals who are adequately prepared to meet the needs of an online hyper---social marketplace, new media curricula must reflect those human--- centered theories and practices found within the discipline of interaction design, in addition to formal new media technical knowledge. The authors propose a new three---by--three theoretical model, referred to as Knowledge---Operators---and---Domains (KOD). Applying this model suggests an approach that extends the practical boundaries of new media to include a range of human--- centered theories and practices, such as ethnography and usability---based studies.
\end{abstract}

\section{Key words}

New media, education, design, ethnography, interaction design, human---centered design

\section{Corresponding author:}

Anthony Faiola, Indiana University School of Informatics, Room IT475, Dean's Suite, Indianapolis, IN 46202, USA Email: Faiola@iupui.edu

This is the author's manuscript of the article published in final edited form as:

Faiola, A., Davis, S. B., \& Edwards, R. L. (2010). Extending knowledge domains for new media education: integrating interaction design theory and methods. new media \& society, 12(5), 691-709. 


\section{Introduction}

New media has ascended to a prominent place in the business, entertainment, education, scientific visualization, and military sectors. This is because new media, roughly synonymous with a range of digital media forms ranging from the Web to handheld devices, entails a high degree of creative and technical convergence as seen in the application of e-commerce, gaming, and a wide range of other interactive and communication technologies. In response to the ascendancy of new media culture in the digital age, colleges and universities started new media programs in the mid-1990s and many of these programs focused on creating innovative projectdriven, skills-based curricula. But many of these same programs have not taught or focused upon usability and interaction design as part of their curricula. However, as the new media marketplace has matured, and has become a powerful venue for the expression of ideas and profitability, there is an increasing demand for interactive and digital products that pass through quality assurance. This will often include product assessments and other methods of usability testing to assure customer satisfaction. While new media faculty provide students with a foundation of design and technical knowledge, they cannot neglect giving adequate attention to those human-centered theories and practices found in interaction design and usability ${ }^{i}$. In this paper, the authors argue that there is a need in new media education for a systematic approach that integrates the knowledge domain of interaction design into new media curricula. A new framework, reflecting human-centered theories found in the discipline of interaction design is crucial for adequately preparing new media students to meet the needs of a hyper-social marketplace.

\section{Building New Media Knowledge}

The interaction design community has an avid interest in what users do. One of the great contributions of classical human-computer interaction (HCI) has been the establishment of usertesting as a fundamental aspect of system design (even though we know that in reality, testing is often done too little, too late, or not at all). While some new media practitioners are happy to proceed on the basis of intuition, an increasing weight is being placed on the validation process obtained through user data analysis and its direct link to product value (Donoghue 2002).

The authors argue that new media programs have to extend their knowledge domains to include interaction design as a core area for teaching and learning. New media faculty must be concerned with teaching those aspects of human factors related to interaction styles and usability. New media courses often focus on software training and design principles, but fail to integrate cognitive theory and conceptual modeling within a design framework (Cockburn \& Bell 1998) that can support a user-centered understanding of product design. As a result, students typically create new media products according to creative models of art and design, but are unprepared to rigorously evaluate those same products according to interaction design principles. Pedagogical models currently employed by some new media programs risk limiting student job opportunities by not equipping them with an adequate understanding of interaction design methodologies. New media students need to learn about the practical relationship between design, media arts technology, and usability. As Foley et al. hold, in a "user-centered economy, usability and attractiveness of the interface is a real marketplace concern" (Foley, Dam, Feiner \& Hughes 1990, p. 392). Furthermore as designer and educator Brenda Laurel (2006) emphatically asserts, based on her first hand experience, "perhaps the most pernicious sort of folly I have seen over 
nearly thirty years in the computer field is the belief on the part of engineers, designers and marketing people is that they 'just know' what will work for their audience" (p.70).

This call for increased attention to interaction design methodologies in new media courses is not just about quantitative approaches and methods. If interaction design practitioners only concentrate on human metrics, thereby failing to grapple with the more qualitative nature of observation, they will miss the more implicit and subtle forms of user behaviour. As a result, performance-based testing, ethnography and other qualitative forms of observation can provide a balance of data gathering techniques in the development of any new media product. Moreover, students must be able to adapt and utilize a full range of innovative thinking and problem-solving skills in designing software and new media products that address our information-rich and socialsensitive culture (Agre 1998).

To meet the needs of the global marketplace and convergence culture, new media education must engage students in regards to the social context of real-world problems. Too often, new media programs teach technology-driven courses that ignore standard usability practices, such as a concern for user preferences or an inquiry into the socio-cultural context of the target audience. Although considerable progress has been made in forming multidisciplinary curricula in new media programs, historically there has been a lack of interest in integrating design and social science methods together. At the very least, current new media curricula need to extend their knowledge domains to address human-centric issues.

As computing becomes ubiquitous, losing its association with particular kinds of hardware, interaction design theory and methods will need to be adopted by, and perhaps subsumed into, new media practicum across a wide range of fields. How new media faculty will respond to these proposed changes in curricula is unclear. Even though most new media programs have been around for less than a decade, multiple pedagogical approaches have been tried and evaluated by most programs. Moreover, new media programs emerged in higher education in a variety of disciplinary settings, and recruited faculty members from an even wider number of disciplines and fields. There will never be a single curricular approach in new media that fits all the possible needs and challenges of such a vast and fast-changing discipline. Nevertheless, we postulate that interaction design methodologies can help address critical issues arising from the changing contexts for and demands on new media educators and propose a pedagogical framework composed of theories and applications that educators may implement in response to those changes.

\section{New Media Education}

Today's new media education continues to evolve from within a range of disciplines, such as art, design, communication, and programs that strictly identify themselves as new media, e.g., those with media arts course content (Faiola 2002). As Figure 1 illustrates, the spectrum of new media ranges from fine arts to TV broadcasting. In this paper, our general use of new media applies to this full range of practices, including new media programs with varying degrees of interaction design theory and methods. As part of their curriculum requirements, new media students frequently are encouraged or mandated to take courses in programming, thereby becoming exposed to some aspects of interaction design. Yet in most new media programs, courses involving interaction design and usability are limited because teaching those theories and methods demands a unique interest on the part of new media faculty. Furthermore, many new media programs do not offer courses that can educate students about the value of the humancentered approach. Educators must have a vested interest in enhancing student knowledge and 
skill-sets that issue in a form of user consciousness. As a result, their approach to new media problem solving will be far more objective in the way they conceptualize interaction design. At the same time, they will include other important design and testing techniques such as information architecture, cognitive modeling, and related aspects of quality assurance that depend on performance and preference testing.

If students have an interest in learning interaction design, but new media programs are not equipped to teach it, students may go elsewhere to find the knowledge and skills they need. If this happens, they may find that new media is rarely discussed in the context of social or usercentered design and development. This is because many technology-centered programs focus on system or software design and testing from the perspective of quality control, rather than user satisfaction or product performance. Although many interaction design principles and practices can be applied to new media, if taught out of context, students may find it difficult to make the connection between building dialogue boxes for software and specific human-centered issues related to the design of new media content.

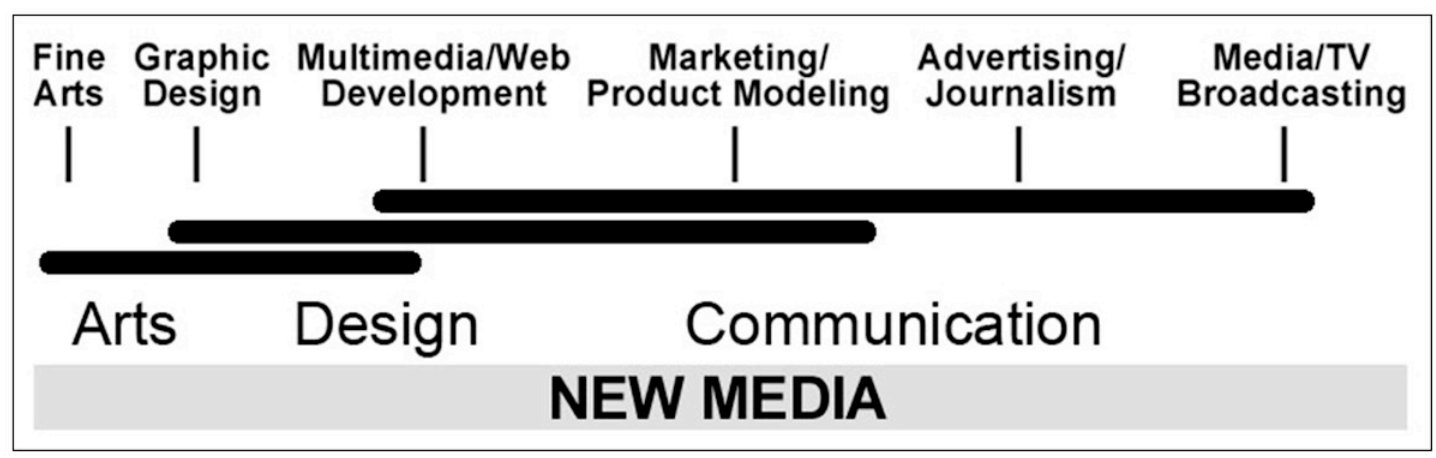

Figure 1. Three disciplines that overlap the broader field of New Media.

Ultimately, students require multiple opportunities to apply well-formed knowledge into activities that address the needs of users or demonstrate an awareness of social context. Without these opportunities, their newly acquired conceptual understanding will remain abstract and possibly erroneous. Furthermore, these new areas of knowledge, having no apparent significance in the real world, will not be readily transferable to other learning situations (Bransford, Sherwood, Hasselbring, Kinzer \& Williams 1990). This idea of learning, which is integrated and grounded in real-world activities, can be traced back to the educational philosophy of Dewey (1933).

Wicklein (1997) concurred when he argued that many programs: 1) "present rigid linear models that relegate students to prescriptive solutions as if there was only one approach to the problem" and 2) "devote the vast majority of classroom time to specific and sometimes obscure technical skill development" (p. 33). Simply put, learning is not a linear process of adding or placing one skill on top of another. Rather, normal pedagogical experiences emerge when students transfer one body of knowledge to another with a contextual application.

Informed by these learning models, the authors hold that new media curricula should provide students with a broader and more unified approach that includes an interaction design perspective. Integrating interaction design from a human-centered perspective into new media curricula will enlarge the new media problem space, i.e. a place where users, technology, and context converge. Our new pedagogical model includes knowledge domains and techniques that draw upon mainstream concerns for socio-cultural context, communication, design strategizing, and media development and testing (Faiola 2007; Faiola 2003). Therefore, our proposed model includes a framework that provides both a theoretical underpinning and a practicum for designing and 
assessing new media products that follow usability guidelines and interaction design methodologies.

\section{The Knowledge-Operators-and-Domains Model}

The authors propose a three-by-three model, referred to as Knowledge-Operators-and-Domains (KOD) (see Table 1). In this model, the Knowledge Domains (ethnography, design, and media) and the Knowledge Operators (theory, application, and management) extend the boundaries of new media theory and practice to include a more integrated approach to knowledge management that is far more centered on user interaction design theory and methods. The KOD model is an argument for a pervasive application of not just human-centeredness, but a humane approach, in which new media developers take into account the differences among individual humans and their needs (Cooper \& Reimann 2003; Raskin 2000).

The KOD framework entails the collection, analysis, and interpretation of human-centered knowledge and its relevance to achieving a more effective design, development, and deployment of new media products. Although the human-centered approach is not new, the proposed KOD model emphasizes a unified structure for managing new media knowledge domains, with an expanded attention to conceptualization, development, and administrative processes.

The KOD model provides educators with a strategic and unified approach to new media development by providing a basic structure to manage knowledge and human assets acquired through processes related to ethnography, media design, and usability testing. This new framework does not displace the need of new media programs to teach design principles. Rather, it encourages new media students to approach "design" not only from creative art perspectives but from the standpoint of design issues "wrought by computer-inflected technologies." For new media students, this includes understanding the difference between "processing data and designing its output" and the "modes and strategies by which the designer organizes it and offers visual, conceptual, and technological affordances to the material" (Lunenfeld 2004, p. 67).

To explain the KOD model (shown in Table 1), we will discuss the meaning, significance and application of each of the three KOD knowledge domains (ethnography, design and media) and their interrelationships. The pedagogical relevance of KOD is its framework of interrelated domains and operations; Table 1 reveals the systematic relationships between each of the knowledge domains and the related knowledge operators (theory, application and management). Ultimately, this framework, initiated with ethnography and contextual inquiry, is a means to obtain and utilize design knowledge to arrive at interactive media that have passed through the scrutiny of usability processes.

\section{Ethnography}

As an interpretive methodology, ethnography has found growing acceptance among software and Web designers as a means to explore the various techniques for testing human-computer interaction (Fetterman 1998; Plowman 2003). As Myers (2004) argues, the main goal of ethnography is to improve our understanding of human thought and action through interpretation of human actions in context. And, as Gouveia and Gouveia (2002) suggest, qualitative findings from ethnographic studies can provide additional results to better inform the design process about the refinement of human measurement.

Ethnographic research has historically been considered an invalid means to secure data while studying information systems. However, Hemmings and Crabtree (2002) argue that the appeal of ethnography follows the recognition by designers that the development of interactive 
systems increasingly relies upon social circumstances. The problem is that traditional techniques systematically deconstruct human action in the work place, and in so doing: 1) obscure or misrepresent the empirical process within a particular socially organized environment and 2) fail to give adequate attention to the social nature of work. On the other hand, the focus of ethnography is on "social practices which enable the very processes which analytic methods identify, but which they decontextualize” (Hughes, King, Rodden \& Andersen 1994, p. 430).

\begin{tabular}{|c|c|c|c|c|}
\hline \multicolumn{5}{|c|}{ KOD MODEL } \\
\hline & & $\begin{array}{l}\text { Eth nography } \\
\text { (Socio-Culture) }\end{array}$ & $\begin{array}{c}\text { Design } \\
\text { (Communication \& Interaction) }\end{array}$ & $\begin{array}{c}\text { Media } \\
\text { (Building \& Testing) }\end{array}$ \\
\hline \multirow{3}{*}{ 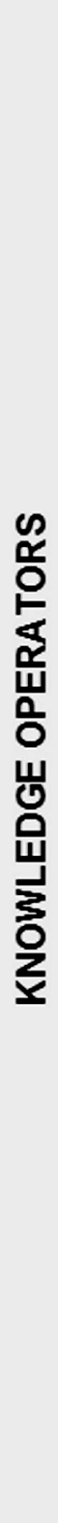 } & 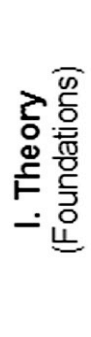 & $\begin{array}{l}\text { - Social Sciences (as applied to HCl) } \\
\circ \text { Psychology (behav. / cog.) } \\
\circ \text { Anthropology / Sociology } \\
\text { - Social computing } \\
\circ \text { Computer-mediated comm. } \\
\circ \text { Computer-supported } \\
\text { collaborative work } \\
\circ \text { Cross-cultural communication } \\
\circ \text { Gaming as social interaction }\end{array}$ & $\begin{array}{l}\text { - Graphic / information design } \\
\text { - Interface design } \\
\text { - Interaction design } \\
\text { - Information visualization } \\
\text { - Human-centered design }\end{array}$ & $\begin{array}{l}\text { - System modeling } \\
\text { - Information architecture } \\
\text { - Computer science } \\
\text { - Usability engineering } \\
\text { - Quality assurance }\end{array}$ \\
\hline & 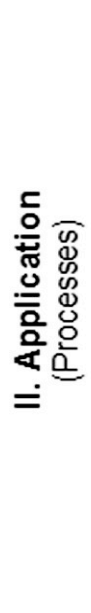 & $\begin{array}{l}\quad \text { Pre-Design } \\
\text { User Requirements: } \\
\text { - Contextual inquiry } \\
\text { - Field/ observational studies } \\
\text { - Interviews \& focus groups } \\
\text { - Questionnaire / surveys } \\
\text { Data Analysis: } \\
\text { - Use cases \& scenarios } \\
\text { - Interpretation / data analysis } \\
\text { - Content analysis }\end{array}$ & $\begin{array}{l}\text { Design } \\
\text { Design Iteration Processing: } \\
\text { - Problem space identification } \\
\text { - Conceptual modeling } \\
\text { - Static (paper) prototyping } \\
\text { - Cognitive or pluralistic } \\
\text { - walkthroughs } \\
\text { - Design iteration }\end{array}$ & $\begin{array}{l}\quad \text { Post-Design } \\
\text { Dynamic Prototype Development: } \\
\text { - Scripting / HTML / Visual Basic } \\
\text { - Flash / Director } \\
\text { - Java / C++ / etc. } \\
\text { Usability Studies: ) } \\
\text { - Quantitative } \\
\text { ○ Performance testing: time- } \\
\text { on-task usability studies } \\
\text { O Heuristic inspections } \\
\text { ○ Predictive modeling } \\
\text { - Qualitative } \\
\text { P Post-task questionnaires } \\
\circ \text { Interviewd \& focus groups }\end{array}$ \\
\hline & 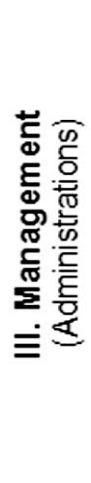 & $\begin{array}{l}\text { Coordinate ethnographic assets } \\
\text { within an interdisciplinary design } \\
\text { team: } \\
\text { - Deploy existing skill-sets through } \\
\text { cross-disciplinary dialogue, thus } \\
\text { facilitating communication that } \\
\text { profits all stakeholders. } \\
\text { - Administrate data gathering } \\
\text { processes; thereby improving the } \\
\text { documentation, organization, and } \\
\text { sharing of contextual-based } \\
\text { requirements information across } \\
\text { knowledge domains. }\end{array}$ & $\begin{array}{l}\text { Based on the requirements data, } \\
\text { direct an informed design that } \\
\text { includes the prototyping of the } \\
\text { system and user interfaces, } \\
\text { including: } \\
\text { - Conceptualization \& design } \\
\text { innovation } \\
\text { - Give attention to visual clarity, } \\
\text { aesthetics, \& other interaction } \\
\text { design issues } \\
\text { - Manage creative design processes } \\
\text { of new technologies that have } \\
\text { portability with functionalities. }\end{array}$ & $\begin{array}{l}\text { Construct the product and } \\
\text { oversee the usability and quality } \\
\text { control of final product } \\
\text { development, such as: } \\
\text { - Product building and testing } \\
\text { - Integration and summation of } \\
\text { data analysis } \\
\text { - Final recommendations }\end{array}$ \\
\hline
\end{tabular}

Table 1. The KOD Framework with three knowledge domains and operators. 
In the context of the KOD model, ethnography, and other social/observational processes (derived from social scientific fields such as psychology and anthropology) are playing a greater role in providing system designers needed support for design decisions from a human-centered perspective. Within the social science domain, interpretive methodologies, such as ethnography, have found acceptance among interaction design professionals as a viable means to inform system design. Nardi (1996) points out that the real significance of these methods has been their ability to make visible to the technologist the objects and processes of a contextually social world.

Ethnographic approaches have been considered since the mid 1980's (Suchman 1987) as a viable approach to providing a more in-depth analysis of system design. The advent of this new tool caused system designers to seriously consider human interaction with computers in social context for the first time. This approach gained momentum when computer systems moved out of the laboratories and into the workplace (Grudin 1990). Hughes et al. (1994) suggest that, "given this turn to the social and the need to study the real world character of work, drifting toward sociology through ethnography is almost a natural inclination" (p. 429). The authors concur in that they believe that social science theory and practice, and the broader inclusion of an interpretive approach, as depicted in the KOD framework, can provide new media students with significant insight into the context of the social and organizational phenomena of new media.

Moreover, ethnography, as taught in the KOD model, provides new media educators and students a way to understand a social setting as it is perceived by those involved in that setting, making the contextual world of the human and computer visible through a detailed description of activities observed (Beyer \& Holtzbalatt 1998; Geertz 1994). It demands a considerable degree of commitment to immerse oneself in a social context to gain a clear understanding of the interactive elements under evaluation. A valuable attribute of ethnography is that it provides information and data to new media designers that cannot be determined through traditional usability methods, such as time-on-task performance studies. Ethnographic methods such as contextual observations, interviews, and focus groups allow designers and users to co-direct a dialogue of inquiry that can get to the heart of user requirements. In this way, both stakeholders arrive at a better understanding of the problem space of a new media product through a co-creative process where ideas and solutions are mutually discovered and shared.

In a new media setting, ethnography is of paramount importance for gathering the requirements needed to understand the crucial relationship between users and new media products. Hence, the traditional utility of new media development, which often lacks the acquisition of contextual knowledge, can be substantially enhanced with processes set in a social setting, with real human-media interactions. Howard (2002) holds that researchers in several disciplines are "navigating a range of methodological challenges in studying essentially the same social phenomena" (p. 551). As scholars are increasingly interested in the behavior of people and organizations that make use of new communication technologies (Howard), new media designers should be especially cognizant of ways to observe the various patterns of behavior that can inform the design process. To do this, ethnography, as one knowledge domain of the KOD model, can help students "adapt their methods in order to best capture evidence" (p. 551), thus providing a better means to describe human behavior based on empirical data.

\section{Design}

\section{Designing for User-Centricity}

In the minds of many academics, design is mere form-making, giving visual style to interactive products, but as Buchanan (2004) states "design ...is not focused solely on form giving” (p. 36). 
Designers "explore not only form and function, but also form and content, since content is what human beings seek in digital experiences" (p. 2). Educators should then direct their students to understand these digital experiences as products of design thinking, while maintaining a profound concern for human-centricity.

Winograd (1996) became the first visible advocate for shifting software engineering away from computing and toward design. During this time, Kapor (1996) argued that although engineering plays an important role in product development, it must take its direction from design to acknowledge the context of use and user needs. He referred to this as a "process of intelligent and conscious design" (p. 4). By the end of the 1990s, we witnessed a gradual acceptance of the human- centered model of teaching interaction design within most design programs in the United States and Europe. This pedagogical shift has redirected the focus from what the computer could do to how users can better interact with them (Shneiderman 2002; Laurel, 2003).

Practitioners, who are increasingly concerned with user-centricity and the social context of computing, are slowly adapting to the displacement of technology as the focal point of new media production. In an attempt to go beyond the cosmetic surface layer of interface design, the notion of "human-centered design" suggests a far more complex problem space of new and emerging technologies that new media faculty must confront. This new theoretical direction of product modeling shows that the theory driving the research is changing, the domains and types of users are diversifying, and what is being designed is significantly different (Barnard, May, Duke \& Duce 2000).

\section{Constructing Design Solutions}

Norman's (1993) early work in the psychology of HCI initiated a fundamental paradigm shift in understanding the development of interactive products. More recently, Norman's (2004) discussion suggests that "affect and emotion are not as well understood as cognition, but are both considered information processing systems, with different functions and operating parameters" (p. 38). He stresses that design affects human emotion and changes how well we perform cognitive tasks. Norman (2004) asserts that good design should now refer to artifacts that "embody both beauty and usability in balance" (p. 40).

This change of emphasis in Norman's writings is further evidence of a move from considering interaction design in terms of simple utility to a richer understanding of other human factors that contribute to the success of new media solutions. For example, despite a wealth of course content dedicated to software training, new media students often lack an adequate understanding of problem-solving as an enterprise of design that maintains its human-centricity. Greenberg (1996) asserts that "good design" is a matter of providing students with knowledge concerning what is usable to people, while implementing the creation of an interface.

DeBono (1990) suggests that the creative process is not objective analysis, but subjective rearrangements of knowledge into restructured patterns of information. Canaan (2005) also argues that "no one ever 'creates' anything; [but rather] ...reorganize[s] existing elements" (p. 236). What interpretation is to ethnography, the convergence of knowledge is to design thinking, and the ushering in of new insights derived from understanding social context of new media technologies. From this point of view, design is a process of human ingenuity, whereby the designer discovers patterns and associations of design knowledge to formulate new solutions that can support new media users.

Another discussion surrounding "design knowledge" centers on the work of Lowgren and Stolterman (2004), who argue that thoughtful interaction design is about design reflection, i.e., a process that is built on a "thorough understanding of the design process, design ability, the designed 
product, and design as part of a larger context" (p. 2). This larger context includes a culture that acknowledges "design as knowledge construction" (p. 2). Here, the emphasis is not placed on artifact production, but rather on "retrospective reflection," where designers provide "arguments and ideas that could explain a specific design" (p. 60). They suggest that this novel perspective of design is a process of design management, or "designing the design process" (p. 41).

Design theories and processes, as outlined in the KOD model, help new media students formalize the conception and management of ideas in response to an existing problem space. Subsequently, design becomes the fusion of ethnographic and creative processes that bond a product's purpose and identity with its value. This implies that new media educators need to understand the enterprise of design as an embodiment of processes, i.e., the sifting, refining, and forming of knowledge through multiple and evolving iterations of conceptualization. As recommended by Lim and Sato (2001), designers - and by extension, new media students - need a more diverse disciplinary perspective from which to develop clear plans to manage knowledge that can inform the creative process of interactive systems. Lim and Sato suggest that within these rather sophisticated design information structures, designers create an "effective knowledge-intensive design environment that reinforces their capability of accessing, exchanging, capturing and generating knowledge in design activities" (p. 33).

Thus far, we have suggested that design is a co-evolutionary process that emphasizes the integration of problem finding and problem solving (Smithers 1998, 2002; Maher 2000; Dorst and Cross 2001). Innovative new media development, as supported in the KOD model, requires that design knowledge be given form through an ethnographic investigation of the problem space. Within such a process, stakeholders, such as clients, users, designers, managers, and others, all share in a "social process" (Lowgren \& Stolterman 2004) of constructing design knowledge. In this scenario, design is not just a series of personal aesthetic choices, but a social process driven by particular social needs related to technology that eventually emerge through data gathering and codesigning (Zamenopoulos \& Alexiou 2004).

Central to our argument is the fact that design is a process of exploration and discovery, wherein the designer "exploits the experience of searching for a problem structure in order to transform an initial belief (insight) into a final design" (Jones 1992, p. 10). In such a participatory and collaborative experience, all processes and participants merge in a well organized framework of domains and operations.

\section{Media}

Media, in the KOD model, is narrowly defined in relation to usability. The third knowledge domain in the KOD framework involves the theory and application of building and assessing the usability of new media products. We argue usability is an important tool for evaluating interactive media forms. Most students in new media programs are able to obtain a relatively solid understanding of communication technology, programming, and graphic software applications by the time they graduate. However, relatively few have a grasp on interaction design theory and usability practice.

For this reason, the KOD model emphasizes the need for usability tools when developing interactive media. Usability (or usability engineering) is derived from human factors, an interdisciplinary field that focuses on the study of human abilities, including memory, learning, and interaction with technology. Although the field of human factors psychology forms much of the basis of usability testing, HCI is a field that seeks to apply the study of human factors specifically to the way humans interact with computer systems, including the logic and functionality of interactive media products.

If provided with the proper knowledge and the incentive to take an analytical approach to 
new media, students can apply a range of validation processes to achieve higher levels of product effectiveness. Through a pragmatic approach to design, development, and testing new media deliverables, the interactive experience for users can improve considerably. As Foley et al. (1990) argue, "good design requires careful consideration of many issues and patience in testing prototypes with real users" (p. 392).

Through new media courses that incorporate a theoretical model focused on designing for human behavior in a contextual world, educators can shape curricula that improve upon those of currently existing new media programs. KOD provides a pedagogical framework in which students learn usability methods that allow for a social scientific approach to collecting and analyzing interpretative and quantitative data to validate product creation. Without such processes of inquiry that provide objective measures, the long-term impact on product quality-in both the classroom and the marketplace - will be evident.

\section{KOD Summary}

While traditional ethnography refers to a set of methods used by anthropologists in field work, it remains a pre-design approach through which new media professionals can make valuable contributions to design. Unlike task analysis methodologies that can also be used in the collection of requirements data, ethnography offers a qualitative means to model new media user expectations. For example, data derived from task analysis techniques or performance-based testing cannot provide insight into an existing new situation or support the envisioning of a new product, because these methods of investigation are focused on a higher level of abstraction. Moreover, the outcome of these techniques typically includes the modeling of procedural knowledge, e.g., cognitive processes relative to physical actions.

In either case, the pre-design approach must include more than a system perspective, while giving more concern for the contextual design of the product. For example, use cases and scenarios, used in conjunction with observational studies and other qualitative forms of engaging target users, can provide foundational knowledge about goal-driven user actions. These methods can provide new media students a means to better understand and gather data about the context of a user's experience and behavior, which in turn, will better inform the conceptual phases of design.

Ethnographic techniques and usability testing are at opposite ends of the design spectrum. Because ethnography is about data discovery and defining the problem space, it is less connected to product quality. At the same time, because usability testing occurs later in the process of product development, it shares a more immediate connection with product quality. But a human-centered experience strategy ensures that new media development is informed and enhanced at every step by user feedback during the ethnographic stage, from which techniques such as prototyping and usability testing can be applied.

In summary, the KOD model provides for the acquisition of knowledge related to pre-design user requirements, product design and development, and product assessment through performance testing and heuristics inspections, as well as other methods of obtaining user feedback. As a result, subjecting new media products to a rigorous system of testing can further validate earlier requirements used to inform design.

\section{Applying KOD \\ New Media Projects}

In the Indiana University-School of Informatics, HCI Graduate Program (IUPUI), the KOD model provides an overarching framework from which course content and related project assignments 
derive cohesion and relevance. As students work through the life-cycle of new media product design, they apply knowledge outlined within the KOD model from lectures, course readings, and class discussions. To allow students to fully benefit from the breadth and depth of the KOD framework, they are guided through a real-world project assignment with a particular theoretical underpinning. The project is placed within the context of a problem space that keeps students focused on the relationship between KOD theory and best practice. In each case, new media knowledge building remains integrally tied to project management and strategizing.

Students work in teams or individually, depending on the class structure. Due to the breadth and depth of the KOD model, it is impossible for any student to acquire all the knowledge domains and operators from one course. Several courses are needed within the HCI program for students to build both core knowledge and new media skills that encompass the scope of the KOD framework. For example, in the two class projects illustrated below, select elements from the KOD model are used. If one compares the following list with Table 1, it is evident which KOD theories and practices have been extracted to complete these projects.

- Ethnography: Defining the problem space and target users, and requirements gathering, i.e., use cases scenarios and interviews; and the analysis of the data.

- Design: Conceptualizing design, interface and interaction design, and paper prototyping.

- Media: Developing interactive prototypes, as well as product evaluations, i.e., usability testing, questionnaires and interviewers.

\section{Focus and Problem Space}

The theoretical focus of this new media class project required students to understand the area of social computing, with direct applications to computer-mediated communication (CMC), e.g., how to design a new media technology that could facilitate social awareness, communication, and interpersonal interaction, as well as the management, dissemination, and accessibility of information. In each case, human-centered design principles were integral to the best practice of ethnography, design, and product development and testing.

The problem space required students to give adequate reflection to the conceptualization of an innovative social computing tool that could enable a transparent and context-aware exchange by means of visual, verbal, or other interactive cues about the presence and activity of all participants. Examples might include systems that enable users to convey attentiveness, emotional conditions, peer pressure, or other forms of communication that are often implicit, ambiguous, or non-existence in traditional forms of CMC. These psychological, or often emotional, conditions of participants are not easily conveyed in the virtual world of online computing. New media technologies might include a combination of distance learning, online forums or chats, 3D gaming spaces, or acquiring, using, and manipulating multiple forms of information, databases, news repositories, etc.

\section{First Student Solution}

The student project example, titled AhHa Learning Environment, was designed as a new media online application that could enable students and instructors to have more intimate synchronous communication. Specifically, the intention of the application was to provide a creative outlet for students and teachers of math and science to share ideas to support online learning. The intentions behind this student project were clear even in the paper prototype phase (see Figure 2). The product was designed to provide a balance between entertainment and education to create strong learning experiences. Aspects of a learning environment often missed in virtual environments, like whispering, outbursts, looking at other students' work, student emotional status, and recognizing question urgency, were addressed and built into this virtual learning space. In Figure 2, for example, 
at the top of the dynamic prototype interface, you have different choices for the "Shout" buttons, such as "Ah ha!, Ughhh," "Got it!" and "Help me!" These choices give the student user a range of emotional statuses related to their current understanding of the course material not commonly offered in virtual learning environments.

The application provided a quick-to-use interface with many horizontal features not requiring the user to dig into the menus, making the interaction features ever-present on the main interface. (See Figure 2) The application will provide tools for communication through text, drawings, and video that is largely organized by the users as well. The primary users will be students and teachers in traditional classrooms or engaged in distance learning. The site will require dynamic content through a scripting language like JSP or ASP to manage data stored in a database or XML documents along with an active media server to handle synchronous text, voice and video options. The site will also provide a highly visual interface via Flash.

Use case scenario: While conducting a live online class/tutor session a teacher may choose to address individual questions in a class of 25 students in a chat session. Each student will be able to see a representation of a question queue and the "bird's eye view" of the class activity to gauge when their question may be addressed. Also, the student questions will be weighted for importance so the instructor can better prioritize student needs. Moreover, the instructor will have a view of all the student icons representing their emotional state. For example, if Jane (student) has an urgent question and does not show engagement with other users, then the teacher will know to communicate with her as soon as possible. At the same time, another student who is anxious to get help will be able to convey their feelings of anxiety through their color profile, while shouting (brief large text visible by everyone) and peeking at other student drawing boards for clues to help their understanding. The student may also chat with other students privately as he/she waits for the teacher to respond.

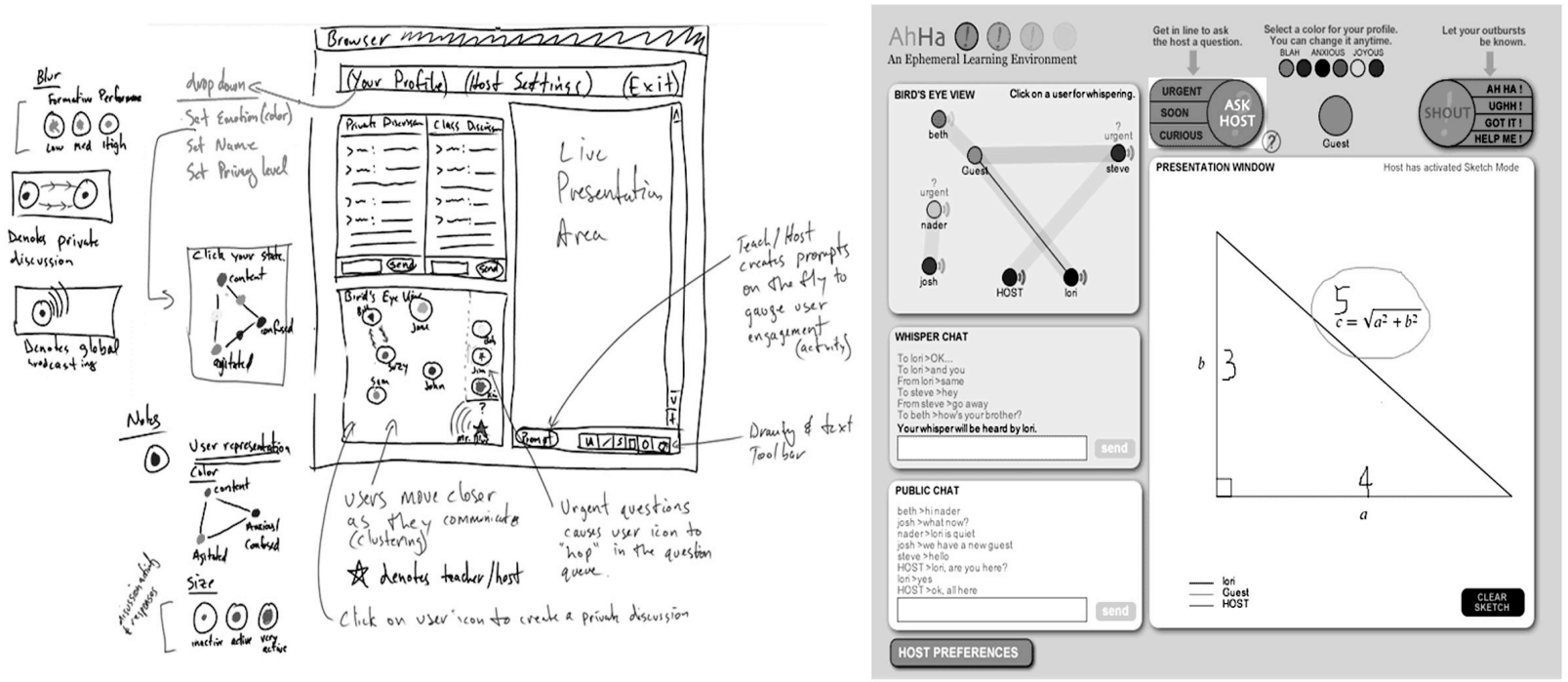

Figure 2. The AhHa Learning Environment interfaces: The paper prototype (L) and dynamic prototype interface $(\mathrm{R})$.

\section{Second Student Solution}

On-the-go professionals, 18 and over, both male and female, are the target users of this worldwide-area network Smart-Phone. This new media system enables users to communicate using 
real-time messaging in chat rooms, sharing videos and photos and a broad range of information, while playing simple turn-based strategy and card games with multiple players. Regarding the technology, a context-aware GPS system is available to locate nearby friends, while cell phone tower pings or direct communication between devices using Bluetooth is also available.

Social computing implications include the ever-increasing pace of modern life that makes it difficult to keep in touch with friends and fellow-students, distant family, and coworkers. It is often impossible to arrange a common time and place to meet, so a flexible communication method is required that allows people to interact from different physical locations and at different times of the day. Users would have the ability to hide their location from other friends if they wish.

Use case scenario: Jocelyn and Zoe agreed to meet at the mall, but Jocelyn cannot find Zoe when she arrives at the predetermined location. It's Saturday night and the mall is crowded and noisy, making voice communication very difficult. Since they both have smart phones with GPS, Jocelyn is able to bring up a map that shows the location of Zoe. The system tells Jocelyn that Zoe is about 100 yards away to the north, right outside the food court. Much to Jocelyn's delight, she sees that her friend Tyra is also only two stores down, so she sends a quick text message to Tyra saying that she and Zoe are meeting at the food court and inviting Tyra to join them there. Figure 3 illustrates what the design for such a system would look like.
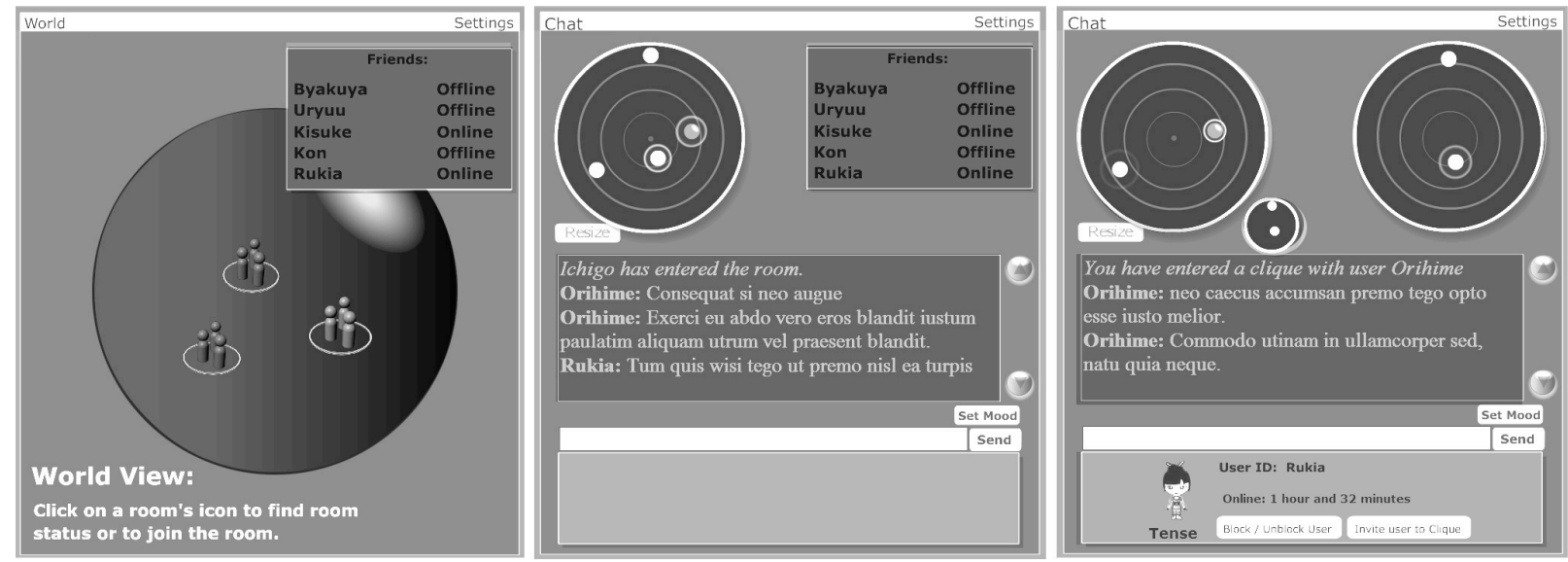

Figure 3. Three prototype interfaces of the "World View" and Chat room.

After devising the adequate user and system requirements through the ethnographic processes, the students were ready to design a compelling and innovative human-centered conceptual model that required reflection on the existing user-media context. They built their final dynamic prototype and applied a range of usability assessment techniques to improve the product.

Through collaborative projects like the two mentioned here, students were able to work out product concepts, functionality, and usability issues, from which they executed the final dynamic prototype. Learning objectives were achieved through course assignments tailored to challenge each student's knowledge and design skills using problem-based scenarios and KOD's design management framework. Management of design knowledge in projects like those cited is essential to the education of future new media professionals. 


\section{Conclusion and Future}

To be competitive in today's new media industry, students must gain learning experiences by solving applied problems in course projects. Companies that provide the best compensation increasingly expect new media specialists to understand the fundamentals of good design, while arriving at product solutions based on user-experience modeling, rather than personal bias. Foley et al. (1990) argued that for interface designers, it is important that their "ego be submerged, so that the user's needs, not the designer's are the driving factor" (p. 392). For this reason, extending the knowledge domains of new media students into interaction design is imperative if they are to grasp the larger context of product development. In addition to the theoretical underpinnings and core knowledge specific to new media, students must have an applied understanding of human factors in new media production, such as the creative management of time and resources, the collaborative problem-solving of a design issue, and the synergistic impact of a team-based strategy.

Increasingly, new media marketing standards will demand higher quality products that secure greater product value and long-term customer satisfaction. Traditional new media theory and methods are essential, but limited, in delivering the full range of knowledge that students need to design integrated communication technologies in an evolving and complex marketplace. To specifically meet these challenges, the KOD model provides a unified and holistic approach for students to connect the profound and often ambiguous aspects of user requirements with the content and design decisions involved in new media production. For this reason, new media scholars, researchers, and instructors must further commit their energies to explore new ways to integrate social science and human-centered theory and practice into class lectures, workshops, and projects.

At the same time, new media educators should have a vested interest in understanding and implementing new pedagogical paradigms that match emerging and rapidly evolving user experiences within an ever-changing convergence culture with innovative technological affordances. For example, personal and social online 3-D spaces like Second Life are changing the user-media interface, where the interaction is no longer composed of clickable points on a flat two-dimensional display. As part of an evolving discipline, new media educators must also reflect upon these new forms of interaction, where users can move in virtual space with the ability to engage and communicate with avatars, as well as construct their own environment.

With the increasing number of skills needed to design and build interactive media, new media students must become proficient in many knowledge domains, processes, and tools, especially those that address the social context of user interaction. In such a learning atmosphere, students can ask questions, obtain answers, and make decisions to build knowledge (Owen 1998) that can inform better decision-making and innovation. By constructing new media curricula that teaches students this broad range of interaction design theories, models, and techniques, educators will open the door to far more opportunities for their students, while addressing the inevitable future of emerging communication technologies.

\section{References}

Agre, P. E. (1998) 'Designing Genre for New Media: Social, Economic, and Political Contexts', in S. J. Jones (ed.). CyberSociety 2.0: Revisiting CMC and Community, Thousand Oaks, CA: Sage, pp. 64-105.

Barnard, P. J., May, J., Duke, D. J. \& Duce, D. A. (2000) 'Systems Interactions and Macrotheory', Transactions on Computer Human Interactions 7: 222-262. 
Beyer, H. \& Holtzbalatt, K. (1998) Contextual Design: Defining Customer-Centered Systems. New York: Morgan Kaufmann Publishers.

Bransford, J., Sherwood, R., Hasselbring, T., Kinzer, C. \& Williams, S. (1990)' Anchored instruction: Why We Need it and How Technology Can Help', in D. Nix. and R. Spiro (eds.). Cognition, Education, and Multimedia: Exploring Ideas in High technology, Hillsdale, NJ: Lawrence Erlbaum Associates, pp. 163-205.

Buchanan, R. (2004) 'Human-Centered Design: Changing Perspectives on Design Education in the East and West', Design Issues 20(1): 30-39.

Canaan D (2005) Research to Fuel the Creative Process. In Laurel B (ed.) Design Research: Methods and Perspectives. pp. 234-240, Cambridge, MA: MIT Press.

Cockburn, A. \& Bell, T. (1998) 'Extending HCI in the Computer Science Curriculum', Proceedings of the Third Australasian Conference on Computer Science Education, Brisbane, Australia (ACM Press), pp. 113-120.

Cooper, A. \& Reimann R. M. (2003) About Face 2.0: The Essentials of Interaction Design. New York: Wiley \& Sons.

DeBono, E. (1990). New Think: The Use of Lateral Thinking in the Generation of New Ideas. New York: Basic Books.

Dewey, J. (1933) How We think: A Restatement of the Relation of Reflective Thinking to the Educative Process. Boston: D. C. Heath.

Donoghue, K. (2002). Built for Use: Driving Profitability Through the User Experience. New York: McGraw Hill.

Dorst, K.\& Cross, N. (2001) 'Creativity in the Design Process: Co-Evolution of Problem-Solution', Design Studies 22(5): 425-437.

Faiola, A. (2002) 'New Media Usability: HCI Curriculum Focus in the School of Informatics', ACM Interactions - New Visions of Human-Computer 9(2): 25-27.

Faiola, A. (2003) 'The Copernican Shift: HCI Education and the Design Enterprise', in J. Jacko and C. Stephanidis (eds.) Human-Computer Interaction-Ergonomics and User Interfaces, Vol. 1. Theory and Practice, Part 1. London: Lawrence Erlbaum Associates, pp. 326-330.

Faiola, A. (2007) 'The Design Enterprise: Rethinking the HCI Education Paradigm', Design Issues. (23)3, 30-45.

Fetterman, D. M. (1998) Ethnography: Step by Step. Thousand Oaks, CA: Sage.

Foley, J. D., Dam, A. V., Feiner, S. and Hughes J. (1990) Computer Graphics: Principles and Practice. New York: Addison Wesley.

Geertz, C. (1994) 'Thick Description: Toward an Interpretive Theory of Culture', in M. Martin and C. C. McIntyre (eds.) Readings in the Philosophy of Social Science, New York: Basic Books, pp. 213-231.

Gouveia, L. B. \& Gouveia, F. (2002) 'Evaluative Ethnography and Systems Design: Can It Also be Used to Assess Presence?', Presentation of the Fifth Annual International Workshop PRESENCE 2002, International Society for Presence Research, Universidade Fernando Pessoa, Porto, Portugal.

Greenberg, S. (1996) 'Teaching Human-Computer Interaction to Programmers', ACM Interactions 3(4): $62-76$.

Grudin, J. (1990) 'The Computer Reaches Out: The Historical Continuity of Interface Design', Proceedings of ACM CHI'90 Conference on Human Factors in Computing Systems, Evolution and Practice in User Interface Engineering, Seattle, WA, pp. 261-268. 
Hemmings, T. \& Crabtree, A. (2002) 'Ethnography for Design?', Proceedings of the International Workshop on Interpretive Approaches to Information Systems and Computing Research, Brunel University, West London, UK, pp. 122-124.

Howard, P. N. (2002) 'Network Ethnography and the Hypermedia Organization: New Media, New Organizations, New Methods', New Media and Society 4(4), 550-574.

Hughes, J. A., King, V., Rodden, T. \& Andersen, H. (1994) 'Moving Out from the Control Room: Ethnography in System Design', Proceedings of the ACM 1994 Conference for Computer Supported Cooperative Work. New York, NY: ACM Press, pp. 429-439.

Jones, J. C. (1992) Design Methods. New York: John Wiley \& Sons.

Kapor, M. (1996) 'A Software Design Manifesto', in T. Winograd, J. Bennett, L. DeYoung, and B. Hartfield (eds.) Bringing Design to Software, New York: Addison Wesley, pp. 1-16.

Laurel, B. (2003). (ed.) Design Research: Methods and Perspectives, Cambridge: MIT Press.

Laurel, B. (2006) 'Brenda Laurel Interview' in Saffer, D. Designing for Interaction: Creating Smart Applications and Clever Devices. Berkeley, CA: New Riders, pp.70-78.

Lim, Y. \& Sato, K. (2001) 'Development of Design Information Framework for Interactive Systems Design', Paper presented at the 5th Asian International Symposium on Design Science, Seoul.

Löwgren, J. and Stolterman, E. (2004) Thoughtful Interaction Design. Cambridge, MA: MIT Press.

Maher, M. L. (2000) 'A Model of Co-Evolutionary Design', Engineering with Computers 16(3-4): 195-208.

Myers, M. D. (2004) 'Ethnographic Research in Information Systems', ISWorld Net Virtual Meeting Center University of Auckland, URL (consulted March 20, 2004): http://ww2.cis.temple.edu/isworld/vmc/aispert/myers.html

Nardi, B. A. (1996) 'Activity Theory and Human-Computer Interaction', in B. A. Nardi (ed.) Context and Consciousness: Activity Theory and Human-Computer Interaction, Cambridge, Massachusetts: The MIT Press, pp. 7-16.

Norman, D. A. (1993) The Design of Everyday Things. New York: Doubleday Currency.

Norman, D. A. (2004). Emotional Design: Why We Love (or Hate) Everyday Things. New York: Basic Book.

Owen, C. L. (1998) 'Understanding Design Research: Toward an Achievement of Balance', Design Studies 19(1): 9-20.

Plowman, T. (2003) 'Ethnography and Critical Design Space,' in Laurel, B. (ed.) Design Research: Methods and Perspectives, Cambridge: MIT Press, pp. 30-38

Raskin, J. (2000) The Humane Interface. New York: Addison-Wesley.

Shneiderman, B. (2002) Leonardo's Laptop: Human Needs and the New Computing Technologies. Cambridge, MA: MIT Press.

Smithers, T. (1998) 'Towards a Knowledge Level Theory of Design Process', in J. S. Gero and F. Sudweeds (eds), Proceeding of the Conference on Artificial Intelligence in Design '98, Lisbon, Portuga, pp: 3-22.

Smithers, T. (2002) 'Synthesis in Design', in J. S. Gero (ed.) Artificial Intelligence in Design, Kluwer Acaemdic Publishers, Dordrecht, pp. 3-24.

Suchman L. A., (1987) Plans and Situated Actions: The Problem of Human-Machine Communication. Cambridge: Cambridge University Press.

Wicklein, R. C. (1997) 'Curriculum Focus for Technology Education', Journal of Technology 
Education, 8(2): 71-78.

Winograd, T., (ed.) (1996) Bringing Design to Software. Reading, MA: Addison-Wesley. Zamenopoulos, T. \& Alexiou, K. (2004) 'Design and Anticipation: Towards an Organisational

View of Design Systems', London: Centre for Advanced Spatial Analysis, University College London Working Papers, URL (consulted December 15, 2005): http://www.casa.ucl.ac.uk/working_papers/paper76.pdf

\footnotetext{
i The phrase "interaction design," for practical purposes, also refers to the core discipline of human-computer interaction (HCI). The field of HCI has existed for over two decades, during which time a substantial degree of discovery has taken place to identify models and methodologies that better address usability and human-centricity in system design. HCI is multidisciplinary, with a broad range of theoretical perspectives, where researchers and system designers explore methodologies that conform to human abilities and needs in context. Hence, when interaction design is used in this paper, it refers to broad range of theories and methods that can lead to the decrease of user error, while increasing the efficiency of task execution. Ultimately, the goal of applying interaction design methodologies is to improve the design and behavior of new media products, i.e., to create products that generate less frustration and higher levels of productivity, including satisfaction for users. Interaction design methods initially include researching and understanding user needs and experiences, then designing to meet and even exceed those needs. Theories include an integration of knowledge domains, such as the cognitive, behavioral, and social aspects of users. Also included in this field is an understanding of those concepts underlying usability engineering techniques such as performance testing, systematic design methods, and ethnography. Related design practices may also include participatory design and contextual design to increase system functionality.
} 